\title{
Liquidity and Arbitrage in Options Markets: A Survival Analysis Approach
}

\author{
LAURENT DEVILLE* \\ FABRICE RIVA $^{\dagger}$ \\ Forthcomming in the Review of Finance
}

\begin{abstract}
This paper examines the determinants of the time it takes for an index options market to return to no arbitrage values after put-call parity deviations, using intraday transactions data from the French index options market. We employ survival analysis to characterize how limits to arbitrage influence the expected duration of arbitrage deviations. After controlling for conventional limits to arbitrage, we show that liquidity-linked variables are associated with a faster reversion of arbitrage profits. The introduction of an ETF also affects the survival rates of deviations but this impact essentially stems from the reduction in the level of potential arbitrage profits.
\end{abstract}

${ }^{*}$ CNRS; DRM-CEREG (UMR 7088); Paris Dauphine University; Place du Maréchal de Lattre de Tassigny; 75775 Paris Cedex 16, France; Tel.: +33 (0)1 440545 36; Fax: +33 (0)1 440540 23; e-mail: Laurent.Deville@ dauphine.fr

'DRM-CEREG (UMR 7088); Paris Dauphine University; Place du Maréchal de Lattre de Tassigny; 75775 Paris Cedex 16, France; Tel.: +33 (0)1 440549 88; Fax: +33 (0)1 440540 23; e-mail: Fabrice.Riva@ dauphine.fr. We gratefully acknowledge the comments and suggestions from Bruno Biais, Hazem Daouk, Thierry Foucault, Christine Parlour, Myron Slovin and Marie Sushka. We would like to thank seminar participants at the 2004 Toulouse Master in Finance Inaugural Conference, the Europlace Institute of Finance November 2004 Research Days, the French Finance Association 2004 Annual Meeting, the FMA 2005 European conference, the 2006 Konstanz International Conference on High-Frequency Finance and the 2006 Banque de France Microstructure of Financial and Money Markets conference. We would also like to thank the editor, Marco Pagano, and an anonymous referee for insightful suggestions. The authors befitted from the financial support of the Europlace Institute of Finance. 


\section{Introduction}

In the absence of arbitrage, two assets providing identical future payoffs must trade at the same price. In an efficient market, any deviation from no arbitrage values must trigger an immediate reaction from market participants, and the rapid disappearance of the mispricing. However, empirical evidence shows that assets can sustain prices that deviate from no arbitrage values for protracted periods of time, suggesting that traders are constrained in their arbitrage activity. Hence, the persistence over time of an arbitrage opportunity should be related to the difficulties that traders confront when they seek to exploit mispricing. In this paper, we investigate this conjecture by analyzing the relationship between the intradaily persistence of deviations from put-call parity on the French index options market and the constraints induced by market liquidity.

The literature on limits to arbitrage identifies various factors that are likely to impede the arbitrage process. First, some deviations may be impossible to arbitrage due to short sales restrictions (Lamont and Thaler, 2003; Ofek et al., 2004). Second, arbitrage may not be riskless: the risks associated with arbitrage include fundamental risk (Campbell and Kyle, 1993), noisetrader risk (DeLong et al., 1990) as well as synchronization risk (Abreu and Brunnermeier, 2002). Finally, transaction costs and holding costs may be sufficiently large to preclude apparent arbitrage opportunities (Tuckman and Vila, 1992; Mitchell and Pulvino, 2001).

Liquidity is another limit to arbitrage that is increasingly attracting attention. Liquidity is a major determinant of arbitrageurs' activity because illiquid markets complicate the completion of trades and make arbitrage both more risky and more costly. The fact that we focus on index derivatives makes liquidity all the more critical because the underlying asset is a basket of many stocks. On index futures markets, Roll, Schwartz and Subrahmanyam (2007) show that the basis mean-reverts faster when the market is more liquid. On index options markets, Kamara and Miller (1995) provide evidence that deviations from put-call parity are related to proxies for liquidity risk. 
In this paper, we develop a structural approach that allows us to relate the duration of arbitrage opportunities to liquidity factors. The speed with which the market reverts to no arbitrage is computed as the time it takes for arbitrage profits to revert to zero after a deviation from putcall parity. We term this measure the time to no arbitrage (TTNA) after Deville (2004). The effect of liquidity factors on this length of time is modelled through survival analysis using an accelerated failure time specification.

Using a sample that comprises the entire set of transactions recorded for the French CAC 40 index options from August 1, 2000 through July 31, 2001, we establish several properties of the TTNA. First, we find that TTNA durations exhibit a decreasing hazard rate. The longer an arbitrage opportunity persists, the lower is the probability that it will disappear in the next instant. Hence, deviations that are not quickly exploited may last for a substantial period of time, implying that these opportunities are not valuable enough to trigger reactions from market participants. Second, after controlling for conventional limits to arbitrage (short sales restrictions, trading costs), we show that liquidity-linked variables, such as the volume in the index constituent stocks and in the options market, the imbalance between put and call options volume and the time to maturity are critical for the speed of reversion of arbitrage profits. Third, our sample also allows us to study how the market reacts to the relaxation of a limit to arbitrage through a natural experiment, namely the inception of the first Exchange Traded Fund (ETF) that replicates the evolution of the CAC 40 index. In a controlled environment, we find that the existence of the ETF is associated with a faster reversion to a state of no arbitrage, but that the major effect of the ETF is to lower the size of initial arbitrage profits.

Our paper is related to the extensive literature on options market efficiency that is based on tests of arbitrage relationships, among which put-call parity has been the most extensively studied. ${ }^{1}$ A major limitation of these tests is that they focus on one dimension of the arbitrage issue, namely the size of arbitrage profits. Although such profits are important when characterizing failures of the no arbitrage relationship, we think that an even more important - and 
complementary - dimension with respect to this issue is the speed at which the market reacts when a deviation occurs. The approach that we use combines both these two dimensions and thus captures more precisely the effects of the limits to arbitrage. Ex ante tests can be viewed as an attempt to introduce a dynamic perspective in the computation of arbitrage profits. Kamara and Miller (1995), for the S\&P 500 index options, Mittnik and Rieken (2000) for the German DAX 30 index options and Deville (2004) for the French CAC 40 index options show that ex ante profits decrease with the length of the no-trade window. Yet, such tests provide at most snapshots of the arbitrage process, and so lack the dynamic analysis provided by our study. In an attempt to introduce a dynamic perspective, Roll, Schwartz and Subrahmanyam (2007) investigate the relationship between the basis and a measure of aggregate liquidity. They provide evidence that the reversion of the basis on S\&P 500 futures contracts occurs faster when aggregate NYSE liquidity is high. Assuming that the basis is governed by an Ornstein-Uhlenbeck process, they infer the speed of reversion from the value of the mean-reverting parameter. One advantage of our approach over theirs, is that it allows to compute the actual reversion time and to model directly the effect of the trading environment on this duration.

Our paper is also related to the growing literature on ETFs. ETFs aim at replicating the performance of their benchmark indices as closely as possible, but unlike conventional mutual funds they are listed on stock exchanges and can be traded intradaily. Therefore, the advent of ETFs removes some of the obstacles that prevented arbitrage trades in index derivatives markets. On index futures markets, consistent with this hypothesis, Park and Switzer (1995), Switzer, Varson and Zghidi (2000) and Kurov and Lasser (2002) show that the size and frequency of deviations decrease once ETFs are traded. On options markets, Ackert and Tian (1998, 2001) find no significant relationship between the occurrence and size of arbitrage profits and the existence of ETFs either on the Toronto Stock Exchange or on the CBOE. However, their analysis relies on closing data and is essentially based on pre-/ post-introduction comparisons, whereas our work uses intraday data and controls for differences in market conditions. 
The remainder of the paper is as follows. Section 2 details how we measure the persistence of arbitrage opportunities and briefly reviews survival analysis methodology. Section 3 describes the data. Section 4 presents the empirical results of our analysis of the arbitrage process. Section 5 analyzes the implications of our results through a sensitivity analysis. We conclude in Section 6.

\section{The survival time of put-call parity deviations}

We consider deviations from put-call parity (PCP). By focusing on periods when PCP is violated, we can identify forces that drive prices back to no arbitrage values without resorting to an option pricing model. We briefly present the well-known put-call parity relationship and our time to no arbitrage measure. Next, we review the specification of survival analysis, which we employ to identify variables that affect the elapsed time to no arbitrage.

\subsection{PUT-CALL PARITY RELATIONSHIP AND ARBITRAGE PROFITS}

Under no arbitrage, whenever put and call options with the same characteristics (exercise price and maturity) exist, their premia must satisfy the put-call parity relationship ${ }^{2}$. Define $C_{t}$ and $P_{t}$, the premium at date $t$ of European call and put options on one index share expiring at date $T$ with an exercise price of $K ; I_{t}$, the index value at date $t ; r$, the risk-free interest rate from date $t$ to date $T$ and $D$, the present value of dividends paid by the index constituent shares from date $t$ to date $T$, expressed in index points for one index share. The put-call parity is:

$$
C_{t}-P_{t}=I_{t}-D-K e^{-r}
$$

If equation (1) does not hold, the call option is either under- or over-valued with respect to the put option and an arbitrage portfolio can be constructed by taking opposite positions in the 'real' and the synthetic call option. These strategies are termed 'long hedge' and 'short hedge', 
respectively, depending on the position that is held on the underlying asset. The initial positive flow, $\pi_{i, t}$, generated by the arbitrage strategy $i$ is:

$$
\pi_{i, t}=q_{i}\left[C_{t}-P_{t}-I_{t}+D+K e^{-r}\right]
$$

where $q_{i}$ takes on the value +1 for long hedge deviations and the value -1 for short hedge deviations. This initial flow represents the ex post arbitrage profit that is obtained from the construction of the portfolio at time $t$. The portfolio is held until expiration, at which time inthe-money options are exercised and the index position closed out, leading to a zero terminal payoff. Conventional arbitrage-efficiency tests on options markets are based on the level of potential profits that can be earned from the exploitation of such opportunities.

\subsection{TTNA AS A MEASURE OF MARKET (IN)EFFICIENCY}

The measure of arbitrage efficiency of derivatives markets that we use is the time to no arbitrage, developed in Deville (2004). We use the term TTNA to measure the elapsed time required for market prices to revert to no arbitrage values, once a deviation has been identified. We compute TTNA as follows. We first match pairs of synchronous transactions of calls and puts having the same characteristics. We compute the initial (ex post) arbitrage profit using equation (2) as a function of prices $P_{t}, C_{t}$ and $I_{t}$ at pairing time, $t$. If the long hedge (short hedge) profit is positive, the pair is classified as a long hedge (short hedge) deviation to put-call parity. We update the value of the three components of the arbitrage portfolio (put, call and index) each time a new transaction occurs ${ }^{3}$ and/or the index value changes. The profit resulting from the construction of the arbitrage portfolio is then re-computed with the new set of prevailing prices using equation (2). The updating process terminates when the profit reaches or drops below zero, at which point prices are compatible with no arbitrage. The time to no arbitrage is thus the elapsed time for the arbitrage profit to go to zero prior to the market close.

Given a profit value $\pi_{i, t}$ greater than zero ${ }^{4}$ at pairing time $t, \operatorname{TTNA}_{i}$ is thus defined as: 


$$
\operatorname{TTNA}_{i}=\min \left\{s \mid \pi_{i, t+s} \leq 0\right\}
$$

The set of options transactions prices and index values recorded before the market close does not necessarily induce a return to no arbitrage prices. After the close, no information regarding the index value or options prices is disseminated until the opening of the market on the following trading day. Rather than use opening prices to continue the computation of TTNA on the next trading day, we terminate our calculations just before the close and refer to this time as the time to censoring. The motivation for this choice is threefold. First, the mechanism by which stock prices, and therefore index values, are determined at the market opening and close (call auction) differs from the one that prevails during the trading session (continuous market). Second, an arbitrary addition of 15.5 hours (the duration of the overnight market closure) to the calculated TTNA would imply that prices did not revert to no arbitrage values in the interim. Third, none of the factors that might explain the persistence of arbitrage opportunities are observable over this period. However, to take into account the possibility that prices may not have converged by the market close, we work with a right-censored distribution of TTNA. For censored observations, the censoring time provides a lower bound for actual duration of deviations, a feature that is explicitly accounted for in our estimations.

\subsection{THE USE OF SURVIVAL ANALYSIS}

Survival analysis provides a means both to model the influence of explanatory variables on times to event and to accommodate censored observations in an efficient way. We briefly review the relevant econometrics.

Let $T$ be a continuous random variable that represents the duration of an arbitrage opportunity. The associated p.d.f. and c.d.f. are denoted $f(t)$ and $F(t)$, respectively. Throughout the analysis, we consider an observation to be 'alive' as long as the profit resulting from an arbitrage portfolio remains strictly positive. An observation is considered 'dead' when the portfolio 
leads to a profit that is less than or equal to zero.

Our study relies on three basic quantities. The survival function, $S(t)=1-F(t)$, gives the probability that an event - that is, an arbitrage opportunity - survives beyond time $t$. The hazard function, $h(t)=f(t) / S(t)$, expresses the probability that an event that has persisted up to time $t$ will terminate in the interval $[t, t+d t)$. We use the integrated hazard function $\Lambda(t)=-\log [S(t)]$ to perform graphical checks of model adequacy, as discussed in section 4.3.

We assume a parametric form for the distribution $f(\cdot)$ of the TTNA, which allows direct computation of the likelihood function for the data. Uncensored observations provide information about the probability that an arbitrage opportunity $i$ has survived to its associated time to no arbitrage, which is equal to the density of $T$ at that time, $t_{i}$. For right-censored observations, we know only that the true time to no arbitrage is greater than the censoring time $C_{i}$. Under the assumption that the censoring time $C_{i}$ is independent from the true time $T_{i}{ }^{5}$ we obtain the likelihood function as:

$$
\mathcal{L}=\prod_{i=1}^{n} f\left(t_{i}\right)^{\delta_{i}} S\left(t_{i}\right)^{\left(1-\delta_{i}\right)}
$$

where $t_{i}=\min \left(T_{i}, C_{i}\right)$, and $\delta_{i}=\mathbf{1}_{\left\{T_{i} \leq C_{i}\right\}}$ is a dummy variable that takes on the value one for uncensored observations and zero otherwise.

Among the alternative structures for the distribution that $T$ may be assumed to be drawn from, we focus on the Weibull distribution since it is both fairly general and mathematically tractable. The Weibull distribution is a two-parameter distribution whose p.d.f. is:

$$
f_{W}(t)=\alpha \lambda t^{\alpha-1} \exp \left(-\lambda t^{\alpha}\right), t>0
$$

with $\alpha>0$ the shape parameter and $\lambda>0$ the scale parameter.

Since we are interested in analyzing the effects of the trading environment on the persistence time of deviations, we incorporate variables into the likelihood function to explain time to no arbitrage. As in Lo et al. (2002), we assume a linear relationship between the log of survival 
time and the covariates (explanatory variables) values, namely:

$$
Y=\log (T)=\mu+\gamma^{\prime} Z+\sigma U
$$

where $\gamma^{\prime}=\left(\gamma_{1}, \ldots, \gamma_{p}\right)$ is a vector of regression coefficients and $U$ is the error distribution. This approach is the classical accelerated failure time (AFT) approach, where the effect of the explanatory variables in the original time scale is to accelerate (decelerate) time by a constant factor $\exp \left(-\gamma^{\prime} Z\right)$ when $\gamma$ is negative (positive). Combining the AFT specification with the Weibull for the baseline distribution, the likelihood function in the presence of right-censoring is given by:

$$
\mathcal{L}=\prod_{i=1}^{n}\left[\frac{1}{\sigma} f_{U}\left(\frac{\log t_{i}-\mu-\gamma^{\prime} Z_{i}}{\sigma}\right)\right]^{\delta_{i}}\left[S_{U}\left(\frac{\log t_{i}-\mu-\gamma^{\prime} Z_{i}}{\sigma}\right)\right]^{\left(1-\delta_{i}\right)}
$$

where $\sigma=1 / \alpha$, and $f_{U}(\cdot)$ and $S_{U}(\cdot)$ denote the p.d.f. and the survival function of the standard extreme value distribution, respectively.

\section{Time to no arbitrage statistics}

We investigate the determinants of TTNA for the CAC 40 index options contract for the 12month period from August 2000 to July 2001. Derivative contracts on CAC 40 are the most actively traded options on the Marché des Options Négociables de Paris (MONEP), the French market for equity and index derivatives. ${ }^{6}$

\subsection{CAC 40 INDEX OPTIONS AND ETFS CONTRACTS ${ }^{7}$}

The CAC 40 index consists of 40 stocks selected from the most actively traded French firms quoted on the Paris "Premier Marché". Its value is calculated continuously as the weighted average market capitalization of the 40 stock prices, and is disseminated every 30 seconds by 
Euronext Paris. The index is managed by an independent committee, the "Conseil Scientifique des Indices", which amends the index to reflect changes in the market or in the market capitalization of constituent stocks.

The CAC 40 index option (ticker PXL) is the MONEP's most active contract. In 2000, PXL contracts accounted for one third of the total open interest and one half of the number of trades on the French options market. From August 2000 through July 2001, on average more than 7 millions contracts traded each month, which represents a 1 billion Euros premium. On the MONEP, orders are sent to a Central Order Book by members and executed according to price/time priority. Committed market-makers continuously compete for the order flow. Market makers have an obligation to maintain a permanent bid-ask spread for option series near the money and must publicly reply to any investor's price demand within 30 seconds by sending bid and offer prices that are binding for two minutes. Transactions on the MONEP are carried out by matching buy and sell orders. Orders offering best execution are given priority, with priority for orders at the same price determined by their time-stamp in the central order book. As is the case for stock trading on Euronext Paris, after a call-auction, binding quotes are continuously issued from 9:02 am to 5:30 pm on the automated system NSC until the closing call-auction at $5: 35 \mathrm{pm}^{8}$

The size of PXL contracts is equal to the value of the CAC 40 index multiplied by one Euro and the tick size is 0.1 index point. This contract is cash-settled ${ }^{9}$ and is composed exclusively of European-style options. Trading covers eight rolling open maturities: three spot months, three quarterly maturities, and two half-yearly maturities. The same expiration months are opened for the futures contract on the CAC 40 index, which is also traded on the MONEP. Strike prices are set at standard intervals of 50,100 or 200 points depending on the expiration date. The series that are opened to trading are not necessarily the same for call and put options. At every moment in time, at least three strike prices are listed: one "at the money" and two "out of the money". New series are created depending on the price changes of the CAC 40 index. 
The CAC 40 Master Unit (the first ETF introduced on Euronext Paris) has traded since January 22, 2001, and in essence replicates the price and performance of the CAC 40 index. Its initial value was $1 / 100^{\text {th }}$ of the index value. Cumulated dividends minus management expenses of $0.30 \%$ are paid on an annual basis. ETFs shares are traded on two parallel markets, each governed by its own set of rules. The primary market is the issuing market, where the creation and redemption of parts of the fund can be carried out. ETFs listed on Euronext can also be traded on its secondary market, NextTrack.

As an open-ended fund, with a net asset value priced daily, the assets under management vary over time, through the creation and redemption of full multiples of 50,000 tradable shares, representing 500 times the CAC 40 index euro-denominated value. ETFs are traded continuously through an electronic order book accessible to both issuers and investors from 9:05 am to 5:25 pm. A closing auction takes place at 5:35 pm. In contrast to the usual French stock market, the presence of committed market participants is mandatory. These provide liquidity by continuously posting quotes in the order book for a minimum order size, with a maximum spread of $0.40 \%$ up to five million Euros for the CAC 40 Master Unit.

\subsection{DATA AND TTNA STATISTICS}

Intraday CAC 40 index values and transactions data on the PXL contract are obtained from the Euronext Paris Market Database from August 2000 to July 2001. This database reports the strike price and the expiration month, as well as time-stamped information such as the premium and the number of traded contracts of all options transactions that occur on the MONEP. Dividends on French stocks are typically paid on an annual basis with a high concentration of payments in May and June. Discrete dividends, obtained from Thomson Financial Datastream, are expressed in terms of CAC 40 index points on a daily basis. For each matching pair, the present value of the dividends paid between the trade and the expiration date is calculated with Euribor used as a proxy for the risk-free interest rate. The source for one week to one year Euribor rates 
is Thomson Financial Datastream. The interest rate used in our computations is the linear interpolation of the nearest Euribor rates.

A matching pair is defined as a call and a put that have the same characteristics (strike price and expiration month) and are traded within a one minute interval. Each pairing is associated with the index value prevailing at the same time, thus avoiding asynchronous bias. We impose the usual exclusion criteria to remove unreliable and/or uninformative quotes from our sample. Options with less than two days and more than one year to expiration as well as trades recorded with a premium less than two index points are excluded from the sample. These observations account for $7.55 \%$ of the 170,946 recorded transactions $(78,887$ call and 92,059 put options). We also exclude from the initial sample 216 pairings for which at least one of the index constituent stocks is subject to a trading halt or suspension. The final sample consists of 4,036 matching pairs, of which 1,621 were recorded before the introduction of the ETF and 2,415 afterwards.

[Table 1 about here.]

The sample of pairings is broadly representative of general options market activity. As reported in Table 1, about $80 \%$ of the pairings correspond to options series that are less than one month to maturity, and the number of pairings decreases with time to maturity. This pattern is consistent with the trading activity on the put and call options series on the MONEP, which is highly concentrated on the nearby maturity. Figure 1 depicts the intraday activity of both put and call options transactions for fifteen-minute intervals. Trading activity decreases slowly from the market opening until 2:00 pm and then increases throughout the afternoon, reaching its maximum at the close. The distribution of pairings follows the same intraday trend. Although the number of matched pairs increases when activity is higher, a substantial number of matching pairs is also recorded in the middle of the day, when the activity is at its lowest.

[Figure 1 about here.] 
Also reported in Table 1 are the times to censoring (Panel A) and times to efficiency (Panel B), computed for the full sample, and for pre- and post-introduction of the ETF samples. $9.76 \%$ of the matching pairs are censored since they do not revert to no arbitrage levels before the market close. For the entire period, the mean (median) time to censoring is 105:12 minutes (31:46 minutes), with a very significant decrease after ETF is introduced: the mean time almost halves and the median time falls to one fifth of its previous level.

[Figure 2 about here.]

Figure 2 depicts the empirical distributions of times to censoring (Panel A) and times to efficiency (Panel B). The distribution of the observations that do not revert to no arbitrage is left-skewed. This representation stems from deviations that are observed shortly prior to the market close. This feature does not preclude the existence of arbitrageurs activity: given the time period to conclude trades and for index moves to occur compared to earlier matchings, these late in the day observations are more likely to survive until the market close. However, the fat right tail is indicative of early identified deviations that persist throughout the trading day. This result is indicative of the existence of limits to arbitrage since it illustrates that some factors may slow down or even stop the reversion of prices to no arbitrage values.

Panel B consists of observations that revert to efficient prices before the end of the trading day. On average, profits remain positive for 17:01 minutes after the identification of an arbitrage opportunity. However, the median TTNA is only 3:33 minutes, with a significant decrease from 4:50 minutes before the introduction of ETFs to 3:10 afterward. From Figure 2, the distribution of TTNA exhibits a fat right tail and is left-skewed. Thus, our sample consists of a high proportion of short TTNAs and a small proportion of very long TTNAs. Most profit opportunities do not persist for more than five minutes but it takes more than one hour for prices to reach levels compatible with no arbitrage for $11.18 \%$ of the uncensored observations, and the maximum TTNA is greater than six hours.

Overall, the market displays considerable efficiency in the sense that prices typically revert 
to no arbitrage levels rather quickly but there also appears to be a considerable degree of variability in the reversion process. The introduction of the ETF is associated with shorter durations since the central values of times to efficiency decrease significantly after the ETF is introduced. This finding suggests that the possibility of trading the index through the ETF enhances the linkage between the options and their underlying markets. However, this preliminary analysis does not account for possible differences in the trading environment that are known to affect arbitrage efficiency (Kamara and Miller, 1995). The analysis we conduct in the next section specifically addresses this problem.

\section{Survival analysis results}

In this section, we examine various factors that influence the persistence of arbitrage opportunities. We first define the specified explanatory variables. We next report the empirical results from the survival analysis and check for the adequacy of our parametrization. Finally we test the robustness of our results in a framework that accounts for the possibility of stale prices.

\subsection{SPECIFICATION OF EXPLANATORY VARIABLES}

The theory of limited arbitrage posits that arbitrage is risky, costly and subject to short sale restrictions. We specify explanatory variables that capture the intensity of these limits at the time matched options trades deviate from put-call parity. High volatility levels of the underlying index increase the likelihood of adverse price movements during the creation of the arbitrage portfolio (Campbell and Kyle, 1993). We measure the index volatility using the high-low Parkinson (1980) estimator. ${ }^{10}$ When deciding to exploit arbitrage signals, traders must balance the observable profit with the costs associated with the arbitrage strategy. Our proxy for the total cost borne by the least-cost arbitrageur is the sum of $1 \%$ of the options price, the daily estimate of the effective spread for the basket of stocks that constitutes the CAC 40 index ${ }^{11}$ plus a short-selling costs of $1 \%$ so that short sellers receive only $99 \%$ of the proceeds (Kamara and 
Miller, 1995). Short-hedge opportunities imply that arbitrageurs short the index. Though short sales are allowed on the French market, the difficulty of shorting the index should be accounted for (Ofek, Richardson and Whitelaw, 2004). We use a dummy variable for the direction of the arbitrage portfolio that takes on the value zero when the index leg of the portfolio is long $\left(q_{i}=+1\right)$ and the value one when it is short $\left(q_{i}=-1\right)$. As ETFs became available on CAC 40 index on January 21, 2001, spot trades in the index are facilitated after this date. Therefore we define a dummy variable that takes on value zero for the period before January 21, 2001 and one for the period after this date.

Another impediment to arbitrage we focus on in this paper is market liquidity. Traders always face a tradeoff between immediacy costs and the risk of adverse price movements when delaying their trades. Illiquid markets make this tradeoff all the more critical and could thus deter traders from entering in arbitrage trades. Hence we hypothesize that TTNA is positively related to illiquidity. We proxy for the liquidity in options markets by the activity on the call and put options contracts as measured by the total number of trades for the series of call and put options included in the arbitrage portfolio, over the corresponding trading day. We also include the maturity and the moneyness of the series as additional proxies for the liquidity of the options since trading generally concentrates on the nearby maturity and on near- and out-of-the-money options contracts. For maturity, we use dummy variables that take on the value one if the option belongs to the corresponding maturity and zero otherwise (Mat1 stands for options that expire by the end of the current month, Mat 2 for options with maturity between two and three months and Mat3 for options with maturity more than three months). Moneyness is measured as $\log \left(\left|I_{t}-K e^{-r}\right| / K e^{-r}\right)$. Existing imbalances in the activity of call and put options series may complicate the execution of the option leg of the arbitrage. We define the imbalance as the differential activity between the two options contracts. Liquidity in the underlying index should also be critical given that the index constitutes one leg of the arbitrage. We proxy for the liquidity in the index by two variables. First, we use the activity on the constituent stocks 
as measured by the total trading volume in billion euro over the corresponding trading day. Second, as the arbitrageurs are given the opportunity to trade the index through the ETF, we also include a variable that takes on the value zero before the introduction of the ETF and the trading volume in the ETF in billion euro after its introduction.

The index value is disseminated every 30 seconds on the basis of the last trading prices of the constituent stocks. Staleness in stock prices may result in the index value not reflecting accurately the price of the underlying basket. Staleness may be related to temporary difficulties in trading a stock and may thus lengthen the return to no arbitrage. For each deviation we compute the duration between the pairing time and the last transaction of each CAC 40 constituent stock. The value for the Staleness variable on a given deviation is defined as the maximum of the $\log$ of the individual durations.

\subsection{EMPIRICAL DETERMINANTS OF THE PERSISTENCE OF ARBITRAGE OPPORTUNITIES}

We use a maximum likelihood approach to obtain estimation results for the time to no arbitrage. The estimation is first performed using an intercept-only specification (with no covariates) to infer the characteristics of the failure mechanism of our sample of TTNAs. We then estimate an accelerated failure time specification to isolate the incidence of the covariates previously defined.

[Table 2 about here.]

Table 2 reports the results for the intercept-only model in the first column. First, the regression coefficients are significantly different from zero, which means that there is significant persistence of arbitrage opportunities. From these coefficients, we can recover the estimated expected and median TTNA as $\Gamma(1+1 / \alpha) / \lambda^{1 / \alpha}$ and $[(\log 2) / \lambda]^{1 / \alpha}$, respectively. Consistent with the summary statistics on TTNA, convergence to no arbitrage exhibits some persistence, the estimated average (median) duration of deviations is $27: 28$ minutes ( $7: 52$ minutes), which are quite long durations. Second, the regression coefficients can be transformed back to the 
original time scale as $\lambda=\exp (-\mu / \sigma)$ and $\alpha=1 / \sigma$. With $\hat{\alpha}$ equal to 0.8432 , the hazard rate is decreasing. ${ }^{12}$ Therefore, the probability that an arbitrage opportunity disappears in the next instant is highest shortly after it is first detected. This is at odds with the common view of arbitrage in which arbitrageurs become sequentially aware of the existence of arbitrage opportunities and survival probabilities decrease with time (Abreu and Brunnermeier, 2002).

Collectively, the estimated durations and the decreasing hazard rate may cast doubt on the existence of traders eliminating arbitrage profits on the French options market. However, our identification of arbitrage signals is based on the value of ex post profits. Hence, consistent with the limits to arbitrage literature, some observations we classify as deviations might prove to be ultimately unprofitable. The signals that are not exploited should persist for a long time before disappearing (if ever) after exogenous index moves. On the other hand, the signals that trigger arbitrage transactions should quickly disappear. In this perspective, the decreasing hazard rate we observe in the cross-section is consistent with the existence of limits to arbitrage restricting the activity of arbitrageurs to a subset of deviations. We will show next that liquidity factors are critical for the actual profitability of deviations from efficiency.

The results of the AFT specification are also reported in Table 2. Model 1 only includes the liquidity and risk covariates, Model 2 also includes transaction costs ${ }^{13}$ and Model 3 includes both transaction costs and ex post profits. The results strongly support the major role that limits to arbitrage play in the process of convergence to no arbitrage. In every regression, the chi-square statistic rejects the null hypothesis that the parameter estimates are jointly zero at near-zero significance levels and most variables are significantly different from zero at the $1 \%$ level. Hence, the persistence time of arbitrage opportunities is systematically related to the proxies we use to measure the intensity of limits to arbitrage.

The results strongly support the role of liquidity as a determinant of time to no arbitrage. The negative coefficient for ActivOpt indicates that the more active the options market, the shorter the time to no arbitrage. The coefficient for RatioOpt is positive, which is consistent with the 
hypothesis that differences in liquidity between call and put options of a given series impede the arbitrage process. Furthermore, the coefficients on variables Mat2 and Mat3 are positive, which supports liquidity considerations since the nearest contracts are the most actively traded ones.

In contrast, Moneyness is never significant at conventional levels although moneyness is usually considered as a proxy of liquidity of options markets (Kamara and Miller, 1995). Our selection process is such that the options series of our dataset necessarily reflect trading features. We require that call and put options trade within one minute to form a matching pair, which produces only a small number of observations for far out-of-the-money series. Studies based on closing data arbitrarily produce observations for every option series for which there has been at least one trade throughout the trading day. By comparison, our sample mainly consists of nearthe-money options series so that the thin trading argument that generally applies to moneyness may not be relevant in our study.

The ease in trading the index also strongly affects the arbitrage process. First, the liquidity of the CAC 40 constituent stocks is critical as indicated by the negative coefficient on the variable ActivCAC, even when arbitrageurs can trade the index through the ETF. Second, the positive coefficient on the variable Direc indicates that short-hedge deviations are more likely to persist than long-hedge deviations. This result is in line with the costs and difficulties associated with taking a short position on the underlying index. In contrast, although the coefficient on the variable Staleness has the expected sign, it is not significant but for Model 3. Temporary difficulties in trading at least one of the index constituent stocks, as captured by our variable, do not have a substantial effect on the persistence of arbitrage opportunities.

We also find evidence of a significant negative relationship between volatility and time to no arbitrage. A priori, the direction of this effect is ambiguous. In line with Campbell and Kyle (1993) and Kamara and Miller (1995), volatility makes arbitrage riskier since it increases the probability that a trader will face adverse price changes by the time the arbitrage portfolio is 
built, which should result in a longer TTNA. Alternatively, there could be a mechanical effect in which greater volatility increases the probability that the index value is consistent with PCP in the next instant. Such a circumstance should occur more frequently in the presence of 'small' arbitrage opportunities. Overall this mechanical effect appears to be the dominant one in our sample.

The negative coefficient for the ETF variable in Model 1 and Model 2 indicates that the introduction of the ETF on the CAC 40 index lessens TTNA, and thus appears to enhance arbitrage across the options and the index markets. However, the coefficient for the variable ActivETF is only significant at the $10 \%$ level in Model 1 and not significant in Model 2 . The liquidity of the ETF, as measured by its trading volume, does not significantly affect the time necessary for the market to recover. This result can stem from the specificities of ETFs which, as open-ended funds, can create or redeem new shares to respond to investor's liquidity needs. Because of this, the liquidity of an ETF ultimately relies on the liquidity of its underlying index. These interpretations are supported by the results we obtain with the introduction of the ex post profit (Model 3) in the analysis. The coefficient associated with the variable ETF remains negative but becomes insignificant. The impact of the ETF availability is partly reflected in the size of the ex post profit and, for a given profit value, the ETF is not a significant determinant of the duration of arbitrage deviations. Deville (2004) shows that the ex post profits on the CAC 40 index options market decrease with the introduction of ETFs. Hence, our results are in line with the perspective that it is the availability of an ETF rather than its trading volume that constitutes a relaxation of a limit to arbitrage. This is in contrast to the findings of Ackert and Tian $(1998,2001)$ that the introduction of ETFs did not contribute to reducing put-call parity ex post profits, either on Canadian or on US markets. Our results are, however, consistent with Switzer, Varson et Zghidi (2000) and Kurov and Lasser (2002) who respectively document a negative relationship between the existence of the SPDR ETF or the QQQ ETF on Nasdaq and the size of arbitrage profits on the corresponding futures contracts. 


\subsection{CHECKING MODEL ADEQUACY}

We perform a graphical (hazard plot) test of goodness-of-fit (Lo, MacKinlay and Zhang, 2002) to determine if TTNAs, conditional on our set of covariates, do follow the postulated censored Weibull distribution. If our specification holds, the integrated hazard $\hat{\Lambda}\left(\left\{\hat{u}_{i}\right\}\right)$ of the standardized residuals $\left\{\hat{u}_{i}\right\}$ where $\hat{u}_{i}=\left(\log T_{i}-\hat{\mu}-\gamma^{\prime} Z_{i}\right) / \hat{\sigma}$, should behave like a censored sample from a standard extreme value distribution. Thus, a plot of $\left\{\hat{u}_{i}\right\}$ against $\left\{\log \left[\hat{\Lambda}\left(\hat{u}_{i}\right)\right]\right\}$ should be a straight line with intercept 0 and slope 1 .

[Figure 3 about here.]

Figure 3 panel B reports the result. For comparison purpose, we also report in panel A the hazard plot for a baseline exponential density. From these plots, it appears that the Weibull specification does a fairly good job at explaining TTNAs whereas the exponential specification is clearly rejected. ${ }^{14}$

\subsection{Robustness CHECKS}

\subsubsection{The incidence of outliers}

The distributions of times to efficiency depicted in Figure 2 raise concerns about the existence of outliers and their incidence on our estimation results. We look further into the causes of these large times to no arbitrage by focusing on the $10.08 \%$ of the deviations that persist more than one hour ${ }^{15}$. Clearly, there must be some serious impediments to arbitrage for these observations.

First, we investigate whether factors not controlled for in the analysis may be responsible for these abnormal durations (e.g. announcements of change in the dividend policy for one of the index constituents or unexpected intraday changes in the interest rates). Would it be the case, any deviation recorded over the deviation window would face the same constraints and exhibit comparable durations. Actually, we find that, in 238 out of 407 cases, deviations persisting for short durations (less than 20 minutes) are also recorded within the same window. 
Second, these abnormal durations fit into the framework of limits to arbitrage since the constraints associated with these observations are more stringent compared with the rest of the sample. In particular, the observations associated with abnormal durations are mostly short hedge deviations (305 out of 407) with a median distance to maturity of 29 days (compared to 15 days), a median of 21 options trades of the same series over the day (compared to 45) and a staleness in the index of 3:42 minutes (compared to 2:35 minutes). In these extreme market conditions, arbitrage signals that initially exhibit a positive profit value are presumably too risky to trigger market reaction.

Finally, these very long durations do not drive the decreasing hazard we document. We performed the analysis excluding the $5 \%$ and the $10 \%$ longest durations, and the $5 \%$ and the $10 \%$ largest profit values. The results, not reported to conserve space, remain qualitatively unchanged and the hazard rate remains decreasing for all subsamples.

\subsubsection{Robustness to stale options prices}

Staleness in the index values is controlled for in the analysis through the introduction of the variable Staleness. Another potential concern is staleness in the options prices. We compute TTNAs with the last options transactions prices although the time between successive options transactions can be long. The options prices we use will be stale if quotes have been revised and no options transactions occurred. ${ }^{16}$ In this situation, our measure only provides an upper bound for the actual duration of the arbitrage opportunity. ${ }^{17}$

While unable to achieve greater precision in computing the TTNAs due to the unavailability of quotes data, we can address this issue by considering a generalized version of our estimation procedure known as interval censoring. ${ }^{18}$ Suppose that, at time 0 , transaction prices first deviate from put-call parity. At time $T_{1}$ a trade takes place on the options market and the associated computed profit is still positive. At possible (uncensored) time $T_{2}$, a new transaction price is recorded, that translates into either a zero or negative computed arbitrage profit. In between, 
quotes might have been revised so that they are consistent with no arbitrage. Accordingly, the likelihood function is modified as follows. For uncensored observations, the probability that an arbitrage opportunity $i$ disappears within the interval $\left(T_{1, i}, T_{2, i}\right]$ is given by $S\left(T_{1, i}\right)-S\left(T_{2, i}\right)$ where $S(\cdot)$ denotes the survival function. For right-censored observations, we know only that the time to no arbitrage is greater than $T_{1, i}$ so that the appropriate quantity is $S\left(T_{1, i}\right)$. Using the same notation as in (4), the likelihood function is then:

$$
\mathcal{L}=\prod_{i=1}^{n}\left[S\left(T_{1, i}\right)-S\left(T_{2, i}\right)\right]^{\delta_{i}} \prod_{i=1}^{n}\left[S\left(T_{1, i}\right)\right]^{\left(1-\delta_{i}\right)}
$$

where $\delta_{i}$ takes on the value one when time $T_{i}$ is uncensored and zero otherwise. Inclusion of covariates follows the same line as in section 2.3 .

[Table 3 about here.]

The intercept-only and ATF results for this interval-censoring specification are reported in Table 3. They are qualitatively unchanged: the hazard rate is decreasing and the estimates exhibit the same signs and significance as in the right-censored analysis. Overall, our approach is robust with respect to the possible existence of stale options prices, and the set of explanatory variables that we employ determines the speed of convergence to no arbitrage.

\section{Implications for the options market efficiency}

We investigate how market conditions impact the probability that an arbitrage opportunity is eliminated through a sensitivity analysis, which allows us to translate the parameter estimates for the different covariates in terms of duration. We use two related measures: the survival function and the hazard rate. For given market conditions $Z_{i}$, we compute the corresponding survival function $S_{W}\left[t \exp \left(-\hat{\gamma}^{\prime} Z_{i}\right)\right]$ and hazard rate $\exp \left(\hat{\gamma}^{\prime} Z_{i}\right) h_{W}\left[t \exp \left(\hat{\gamma}^{\prime} Z_{i}\right)\right]$ using the Weibull specification for the baseline functions $S_{W}$ and $h_{W}$. The analysis is performed for se- 
lected determinants by allowing the continuous explanatory variable of interest to take on $10 \%$, $25 \%, 50 \%, 75 \%$ and $90 \%$ percentile values while all other explanatory variables are held fixed at their sample median value. ${ }^{19}$

[Figure 4 about here.]

The survival curves depicted in figure 4 exhibit a decreasing convex pattern that stems from the decreasing hazard we document in Section 4.2. Differences in convexity indicate how the hazard rate decreases in a given explanatory variable. We first analyze the influence of maturity. For the longest maturities, the estimated probability that an arbitrage opportunity survives after 20 minutes is $54.66 \%$, with a corresponding $16.99 \%$ probability for the shortest maturity. It takes 4:26 minutes for half of the opportunities to disappear for the shortest maturities whereas $78.96 \%$ are still alive at the same time if the underlying options are to expire after three months. The instantaneous failure rate associated with one-month contracts is $193 \%$ higher compared with the contracts associated with the longest maturities. These results suggest that the nearby maturity is the most intensively monitored by market participants and thus we focus on this specific contract in the remainder of the analysis.

The other liquidity variables (ActivOpt, RatioOpt and ActivCAC), though statistically significant, yield smaller differences in the survival and hazard rates of arbitrage opportunities. Although the impact of each of these variables is weak, summing their marginal effects implies important differences in a high liquidity / low liquidity scenario comparison. Setting these variables to their best $10 \%$ values results in a hazard rate that is $147 \%$ higher than for the worst $10 \%$ values. This result, combined with the major impact of maturity, illustrates the key impact of liquidity on the failure rate of arbitrage opportunities in the options market, as seen in the 'Comparative scenarios' figure. Illiquidity appears as a major economic determinant of the persistence time of arbitrage deviations.

The patterns associated with volatility do not generate substantial differences in the hazard rate. We previously documented a mechanical effect associated with volatility. Although this 
effect is statistically significant, its economic relevance is small. Under median conditions for volatility (14.30\% annual), we estimate that $31.64 \%$ of the deviations should still be profitable after ten minutes. With a volatility equal to its 10 th percentile value $(6.78 \%$ annual), the estimated survival probability rises to only $35.35 \%$. In terms of hazard rates, halving the volatility results in a decrease of but $9.63 \%$, so that volatility per se has only a marginal effect on the speed of convergence to no arbitrage. This weak effect may be due to the ambiguous effect that volatility has on time to no arbitrage, with the mechanical effect counterbalanced by a risk effect.

Finally, the availability of an ETF tracking the index leads to lower estimated survival probabilities. It takes 1:05 minute for the market to eliminate $25 \%$ of the deviations when the ETF exists against 1:50 minutes before its introduction. The next $25 \%$ are eliminated in the subsequent 3:21 minutes in the former case versus 5:41 minutes in the latter. These results show that the relaxation of a limit to arbitrage, in this case the introduction of the ETF, results in faster convergence of prices to no arbitrage values.

\section{Conclusion}

On options markets, deviations with respect to arbitrage relationships are temporary. We show that, eventually, prices typically revert to no arbitrage levels but the time it takes for reversion to occur exhibits substantial variation. Using survival analysis, we analyze the properties of this time for the French index options market and relate it to the constraints investors confront in their arbitrage activity. We find that a Weibull distribution together with an accelerated failure time specification provides a sensible fit to the durations of inefficiencies. We show that the survival time of arbitrage opportunities exhibits a decreasing hazard rate: the probability of an arbitrage opportunity disappearing in the next instant is at its highest shortly after it has been detected. This "early failure" feature is consistent with the existence of limits to arbitrage 
restricting the activity of arbitrageurs to a subset of deviations.

We find that the persistence time of arbitrage opportunities is systematically related to conventional limits to arbitrage but also to the liquidity of the index and options markets. In particular, we show that liquidity-linked variables, such as the volume on the options market, the imbalance between put and call options volume, the trading volume of the index constituent stocks and the time to maturity are critical for the speed of reversion of arbitrage profits. Furthermore, the results of the sensitivity analysis illustrate the significance of the joint incidence of liquidity variables: the probability of a deviation returning to no arbitrage values in the next instant is $147 \%$ higher on a liquid market than it is on an illiquid market.

The results show that the introduction of an ETF affects survival rates enough to produce highly noticeable differences in expected duration. However, it appears that this impact essentially stems from the reduction in the level of potential arbitrage profits. Nonetheless, if the speed of reversion to no arbitrage values is considered a measure of efficiency, then ETFs appear to be a valuable lever for increasing the degree of efficiency the market can achieve. 


\section{References}

Abreu, D., and M. Brunnermeier, 2002, Synchronization risk and delayed arbitrage, Journal of Financial Economics 66, 341-360.

Ackert, L., and Y. Tian, 1998, The introduction of Toronto Index Participation Units and arbitrage opportunities in the Toronto 35 index option market, Journal of Derivatives 5, 44-53.

— , 2001, Efficiency in index options markets and trading in stock baskets, Journal of Banking and Finance 25, 1607-1634.

Bharadwaj, A., and J. Wiggins, 2001, Box spread and put-call parity tests for the S\&P 500 index LEAPS market, Journal of Derivatives 8, 62-71.

Billingsley, R., and D. Chance, 1985, Options markets efficiency and the box spread strategy, Financial Review 20, 287-301.

Campbell, J., and A. Kyle, 1993, Smart money, noise trading and stock price behaviour, Review of Economic Studies 60, 1-34.

Capelle-Blancard, G., and M. Chaudhury, 2001, Efficiency tests of the French index (CAC 40) options market, Working paper, McGill University.

Cassese, G., and M. Guidolin, 2001, Pricing and informational efficiency of the MIB30 index options market, Working paper, University of Southern Switzerland.

Cavallo, L., and P. Mammola, 2000, Empirical tests of efficiency of the Italian index options market, Journal of Empirical Finance 7, 173-193.

Chance, D., 1987, Parity tests of index options, Advances in Futures and Options Research 2, 47-64.

Chesney, M., R. Gibson, and H. Loubergé, 1995, Arbitrage trading and index option pricing at SOFFEX: An empirical study using daily and intradaily data, Finanzmarkt und Portfolio Management 9, 35-60.

De Long, B., A. Shleifer, L. Summers, and R. Waldmann, 1990, Noise trader risk in financial markets, Journal of Political Economy 98, 703-738.

Deville, L., 2004, Time to efficiency on options markets and the introduction of ETFs: Evidence from the French CAC 40 index, Working Paper, Paris Dauphine University.

Evnine, J., and A. Rudd, 1985, Index options: The early evidence, Journal of Finance 40, 743-756.

Finucane, T., 1991, Put-call parity and expected returns, Journal of Financial and Quantitative Analysis 26, 445-457. 
Gould, J., and D. Galai, 1974, Transaction costs and the relationship between put and call prices, Journal of Financial Economics 1, 105-129.

Kamara, A., and T. Miller, 1995, Daily and intradaily tests of put-call parity, Journal of Financial and Quantitative Analysis 30, 519-539.

Klein, J., and M. Moeschberger, 2003, Survival Analysis: Techniques for Censored and Truncated Data . Statistics for biology and health (Springer) 2nd edn.

Klemkosky, R., and B. Resnick, 1979, Put-call parity and market efficiency, Journal of Finance 34, 1141-1155. 378.

Kurov, A., and D. Lasser, 2002, The effect of the introduction of Cubes on the Nasdaq-100 index spot-futures pricing relationship, Journal of Futures Markets 22, 197-218.

Lamont, O., and R. Thaler, 2003, Can the market add and subtract?: Mispricing in tech-stock carve-outs, Journal of Political Economy 111, 227-268.

Merton, R., 1973, The relationship between put and call prices: Comment, Journal of Finance $28,183-184$.

Mitchell, M., and T. Pulvino, 2001, Characteristics of risk and return in risk arbitrage, Journal of Finance 56, 2135-2176.

Mittnik, S., and S. Rieken, 2000, Put-call parity and the informational efficiency of the German DAX-index options market, International Review of Financial Analysis 9, 259-279.

Ofek, E., M. Richardson, and R. Whitelaw, 2004, Limited arbitrage and short sales restrictions: Evidence from the options markets, Journal of Financial Economics 74, 305-342.

Parkinson, M., 1980, The extreme value method for estimating the variance of the rate of return, Journal of Business 53, 61-65.

Puttonen, V., 1993, Boundary conditions for index options: Evidence from the Finnish market, Journal of Futures Markets 13, 545-562.

Roll, R., 1984, A simple implicit measure of the effective bid-ask spread in an efficient market, Journal of Finance 39, 1127-1139.

E. Schwartz, and A. Subrahmanyam, 2007, Liquidity and the law of one price: The case of the futures-cash basis, Forthcomming in The Journal of Finance.

Stoll, H., 1969, The relationship between put and call option prices, Journal of Finance 24, 801-822. 
Switzer, L., P. Varson, and S. Zghidi, 2000, Standard and Poor's Depository receipts and the performance of the S\&P 500 index futures market, Journal of Futures Markets 20, 705-716.

Tuckman, B., and J.-L. Vila, 1992, Arbitrage with holding costs: A utility based approach, Journal of Finance 47, 1283-1302.

Wagner, D., D. Ellis, and D. Dubofsky, 1996, The factors behind put-call parity violations of S\&P 100 index options, Financial Review 31, 535-552. 


\section{Notes}

${ }^{1}$ Put-call parity empirical studies on the US markets include Gould and Galai (1974) on OTC options, Klemkoski and Resnick $(1979,1980)$ on stock options traded on the CBOE, Ofek et al. (2004) on stock options traded on U.S. exchanges, Evnine and Rudd (1985), Chance (1987), Finucane (1991) and Wagner et al. (1996) on S\&P 100, and Kamara and Miller (1995), Ackert and Tian (2001) and Bharadwaj and Wiggins (2001) on S\&P 500. The latter two studies test other arbitrage relationships, such as the box-spread, also tested by Billingsley and Chance (1985), Chance (1987) and Ackert and Tian (1998). For empirical tests of arbitrage relationships on index options contracts in European markets, see Puttonen (1993) for the Finnish market, Chesney et al. (1995) for the Swiss market, Cavallo and Mammola (2000) and Cassese and Guidolin (2001) for the Italian market, and Capelle-Blancard and Chaudhury (2001) and Deville (2004) for the French market.

${ }^{2}$ Put-call parity was formalized by Stoll (1969) for at-the-money options and extended for non-payout protected options on dividend paying shares by Merton (1973).

${ }^{3}$ Multiple transactions for options having the same characteristics are at times recorded during the same minute, with different transaction prices. In this case, we keep the premium that leads to the smallest profit. In the case of long hedges (short hedges), we therefore use the most (less) expensive calls and the less (most) expensive puts. As a result, we obtain a lower bound for TTNA. We have also estimated an upper bound by deriving the profit with the premium that leads to the highest value. Results, available on request, are only marginally modified since transactions, when recorded simultaneously, rarely exhibit significantly different premia.

${ }^{4}$ Alternatively, the updating process can be stopped as soon as the profit drops below an arbitrary efficiency boundary $\varepsilon>0$ rather than zero. Results based on this specification with $\varepsilon$ set to 1 and 5 index points remain qualitatively unchanged.

${ }^{5}$ In our case, time to censoring (i.e. time to close) provides no information about what would have been the true time to no arbitrage.

${ }^{6}$ Since the December 2001 acquisition of LIFFE (the London International Financial Futures and Options Exchange) by Euronext, French derivatives trading takes place on Euronext.liffe.

${ }^{7}$ Descriptive information in this subsection applies to the sample period of our study. There have been some subsequent changes in the expiration date. For contracts expiring after September 2004, expiration date has moved from the last trading day of the expiration month to the third Friday of the expiration month and fourteen instead of eight maturities are traded.

${ }^{8}$ On 23 April 2001, Euronext implemented a common market model in its three constituent market places: Paris, Amsterdam and Brussels. The continuous trading period now ranges from 9 am for the open to 5:25 pm for 
the close, followed by a closing call auction (fixing) at $5.30 \mathrm{pm}$.

${ }^{9}$ The settlement value is equal to the mean of all index values calculated and disseminated between $3: 40 \mathrm{pm}$ and 4:00 pm on the expiration day.

${ }^{10} \mathrm{We}$ first compute a 10 -minute volatility from the 20 index values that immediately precede a given matching using the high-low Parkinson (1980) estimator $\hat{\sigma}_{10}=\left(\log I_{\max }-\log I_{\min }\right) /(2 \sqrt{\ln 2})$ where $I_{\max }$ and $I_{\min }$ are the maximum and the minimum of the index value over the 10-minute interval. We then transform the 10-minute volatility into an annual volatility using the standard annualization formula. Notice that the Parkinson estimator requires regularly-spaced price series, and is therefore applicable since the CAC 40 index value is disseminated every 30 seconds.

${ }^{11}$ For each day, we first estimate, for each stock in the CAC 40 index, the percentage effective spread following Roll (1984). We then compute the effective spread for the basket as the value-weighted average of the CAC 40 index constituent stocks spread estimates.

${ }^{12}$ The Weibull distribution can accommodate increasing, constant or decreasing hazard depending on the value of the shape parameter. The intercept-only specification is necessary as the constant $\mu$ is contaminated in the AFT regression by the presence of the dummy variables on maturity, on the direction of the deviation and on the existence of the ETF that replicates the CAC 40 index.

${ }^{13}$ In addition to the specification of the transaction costs presented in Section 4.1. we also consider an alternative in which, after the introduction of the ETF, the cost of trading the index is measured by the percentage effective spread of the ETF. Results, available upon request, are unchanged.

${ }^{14} \mathrm{We}$ also examined the performance of other common distributions such as log-logistic and log-normal. The hazard plots we obtained yield clearly inferior, though acceptable fit, compared with the Weibull specification. We also tried to fit the data using a generalized gamma specification, but were unable to get a converging result when performing the likelihood maximization. All results are available upon request.

${ }^{15}$ Out of the 407 deviations that exhibit durations longer than one hour, 260 return to values compatible with no arbitrage and 147 are censored.

${ }^{16}$ Staleness should not be an issue for the identification of initial deviations since (i) we use trade prices and (ii) we impose a tight synchronicity constraint for the transaction time of the three instruments that form the arbitrage portfolio. When we relax the synchronicity constraint and match option trades within a two-minute window instead of one, we obtain qualitatively unchanged results with 2102 additional observations: the proportion of outliers (TTNA longer than one hour) is not significantly different and regression coefficients keep the same sign and significance. As a further check,we also performed the analysis using a more recent dataset in which trades are 
time-stamped to the nearest second. Results (available upon request) with put and call transactions matched within 30 seconds are qualitatively unchanged.

${ }^{17}$ We thank Thierry Foucault for making this point.

${ }^{18}$ In medical trials, interval censoring occurs when patients have a periodic follow-up examination (e.g. every two weeks) so that the patients' event time is only known to fall in an interval. See Klein and Moeschberger (2003).

${ }^{19}$ When fixed, dummy variables are assigned the following values: Direc $=0, \mathrm{ETF}=1$, Mat2 $=0$, Mat3 =0, so that computations are performed for long-hedge deviations in the presence of the ETF for the nearby maturity. 
Table 1: Time to no arbitrage summary statistics

Descriptive statistics of our sample of put-call parity matching pairs (upper part of the Table) are reported by time to maturity, and descriptive statistics of the calculated times to censoring (Panel A) and times to efficiency (Panel B) are reported both for the whole period and for the periods before (August 1, 2000 to January 21, 2001) and after (January 22, 2001 to July 31, 2001) the introduction of the CAC 40 Master Unit ETF. Times are expressed in minutes and seconds. T-stat. and Mann-Whitney stat. reported in the "Post-ETF period" column test the equality between pre- and post-ETF central values. Asterisks ${ }^{* * *}$ denote the rejection of the null hypothesis at the $1 \%$ level in a bilateral test.

\begin{tabular}{|c|c|c|c|}
\hline & Full sample & Pre-ETF period & Post-ETF period \\
\hline Observations & 4,036 & 1,621 & 2,415 \\
\hline \multicolumn{4}{|l|}{ by time to maturity } \\
\hline less than 1 month & 3,219 & 1,335 & 1,884 \\
\hline 2-3 months & 516 & 191 & 325 \\
\hline 4-12 months & 301 & 95 & 206 \\
\hline \multicolumn{4}{|c|}{ Panel A: no reversion to efficient prices before the market close } \\
\hline Number & 394 & 159 & 235 \\
\hline Proportion $(\%)$ & 9.76 & 9.81 & 9.73 \\
\hline \multicolumn{4}{|l|}{ Time to censoring } \\
\hline Mean & 105:12 & $140: 31$ & $81: 18$ \\
\hline T-stat. & & & $4.162^{* * *}$ \\
\hline Median & $31: 46$ & $64: 5 \overline{6}$ & $12: 51$ \\
\hline Mann-Whitney stat. & & - & $19.014^{* * *}$ \\
\hline \multicolumn{4}{|c|}{ Panel B: return to efficient prices before the market close } \\
\hline Number & 3,642 & 1,462 & 2,180 \\
\hline Proportion $(\%)$ & 90.24 & 90.19 & 90.27 \\
\hline \multicolumn{4}{|l|}{ Time to no arbitrage } \\
\hline Mean & 17:01 & $21: 52$ & $13: 46$ \\
\hline T-stat. & & - & $5.822^{* * *}$ \\
\hline Median & $3: 33$ & $4: 5 \overline{0}$ & $3: 10$ \\
\hline Mann-Whitney stat. & & - & $70.426^{* * *}$ \\
\hline
\end{tabular}


Table 2: Empirical results for the survival analysis of deviation durations

The maximum likelihood estimates, with the corresponding standard errors and z-statistics are reported in Panel A for the intercept-only model (with no covariates) and three specifications of the AFT model given in equation (6). The dependent variable is the time to no arbitrage (or time to censoring) measured in seconds. For the AFT model, the explanatory variables (covariates) are (i) the total number of transactions for the series of call and put options that are included in the arbitrage portfolio over the day (ActivOpt); (ii) the imbalance between the call and put options transactions (RatioOpt); (iii) and (iv) the maturity of the series (Mat2, Mat3); (v) the moneyness of the option series (Moneyness); (vi) the direction of the deviation (Direc); (vii) the total volume traded for the CAC 40 index constituting stocks over the day (ActivCAC); (viii) a measure of the staleness in the index values (Staleness); (ix) the index volatility (Volat); (x) the availability of the CAC 40 ETF (ETF) and (xi) the total volume traded for the CAC 40 ETF over the day (ActivETF). Model 2 also includes (xii) the explicit transaction costs (Costs) and Model 3 includes (xiii) the value of the initial ex-post profit (Profit). Log-likelihoods and log-likelihood tests between the intercept-only and the AFT specifications are reported in Panel B. The null hypothesis for the $\chi^{2}$ test statistic is that the covariates do not improve the explanatory power of the model. Asterisks ${ }^{* * *},{ }^{* *},{ }^{*}$ denote the rejection of the null hypothesis at the $1 \%, 5 \%$ and $10 \%$ levels, respectively, in a bilateral test. The likelihood ratio statistics for model 1, model 2 and model 3 follow a $\chi^{2}$ distribution with 11,12 and 13 degrees of freedom, respectively.

\begin{tabular}{|c|c|c|c|c|c|c|c|c|}
\hline \multicolumn{9}{|c|}{ Panel A: Parameter estimates } \\
\hline \multirow[b]{2}{*}{ Variable } & \multicolumn{2}{|c|}{ Intercept-only model } & \multicolumn{2}{|c|}{ Model 1} & \multicolumn{2}{|c|}{ Model 2} & \multicolumn{2}{|c|}{ Model 3} \\
\hline & Coefficient & Z-stat. & Coefficient & Z-stat. & Coefficient & Z-stat. & Coefficient & Z-stat. \\
\hline$\mu$ (intercept) & $6.839^{* * *}$ & 214.70 & $7.991^{* * *}$ & 34.13 & $7.671^{* * *}$ & 28.87 & $6.233^{* * *}$ & 24.61 \\
\hline $\log \sigma$ & $0.621^{* * *}$ & 51.60 & $0.473^{* * *}$ & 38.92 & $0.473^{* * *}$ & 38.94 & $0.395^{* * *}$ & 33.71 \\
\hline ActivOpt & & & $-0.009^{* * *}$ & -8.11 & $-0.008^{* * *}$ & -7.05 & $-0.007^{* * *}$ & -6.06 \\
\hline RatioOpt & & & $0.007^{* * *}$ & 4.63 & $0.007^{* * *}$ & 4.55 & $0.005^{* * *}$ & 3.56 \\
\hline Mat2 & & & $0.676^{* * *}$ & 7.46 & $0.559^{* * *}$ & 5.50 & $0.476^{* * *}$ & 5.02 \\
\hline Mat3 & & & $2.157^{* * *}$ & 16.37 & $1.727^{* * *}$ & 8.13 & $0.951^{* * *}$ & 4.81 \\
\hline Moneyness & & & 0.008 & 0.38 & -0.019 & -0.79 & -0.003 & -0.13 \\
\hline Direc & & & $0.328^{* * *}$ & 5.85 & $0.312^{* * *}$ & 5.53 & $0.145^{* * *}$ & 2.80 \\
\hline ActivCAC & & & $-0.229^{* * *}$ & -6.21 & $-0.241^{* * *}$ & -6.48 & $-0.101^{* * *}$ & -2.92 \\
\hline Staleness & & & 0.043 & 1.64 & 0.039 & 1.51 & $0.061^{* *}$ & 2.48 \\
\hline Volat & & & $-0.021^{* * *}$ & -8.07 & $-0.022^{* * *}$ & -8.41 & $-0.019^{* * *}$ & -7.68 \\
\hline ETF & & & $-0.559^{* * *}$ & -6.45 & $-0.526^{* * *}$ & -6.01 & -0.118 & -1.44 \\
\hline ActivETF & & & $-3.485^{*}$ & -1.74 & -3.035 & -1.51 & 2.491 & 1.33 \\
\hline Costs & & & & & $0.095^{* *}$ & 2.53 & -0.018 & -0.48 \\
\hline Profit & & & & & & & $0.176^{* * *}$ & 26.48 \\
\hline \multicolumn{9}{|c|}{ Panel B: Likelihoods and likelihood ratio test (Intercept-only vs AFT specification) } \\
\hline Log-likelihood & \multicolumn{2}{|c|}{$-28,800.3$} & \multicolumn{2}{|c|}{$-28,243.8$} & \multicolumn{2}{|c|}{$-28,240.6$} & \multicolumn{2}{|c|}{$-27,816.8$} \\
\hline$\chi^{2}(p$-value $)$ & \multicolumn{2}{|l|}{ _- } & \multicolumn{2}{|c|}{$1,112.9(<0.001)$} & \multicolumn{2}{|c|}{$1,119.5(<0.001)$} & \multicolumn{2}{|c|}{$1,967.0(<0.001)$} \\
\hline
\end{tabular}


Table 3: Survival analysis results with interval-censoring

The maximum likelihood parameter estimates, with the corresponding standard errors and z-statistics are reported for the 4,252 sample matchings both for the intercept-only (Panel A) and the Accelerated Failure Time (Panel B) specifications with interval-censoring. The explanatory variables (covariates) are (i) the total number of transactions for the series of call and put options that are included in the arbitrage portfolio over the day (ActivOpt); (ii) the imbalance between the call and put options transactions (RatioOpt); (iii) and (iv) the maturity of the series (Mat2, Mat3); (v) the moneyness of the option series (Moneyness); (vi) the direction of the deviation (Direc); (vii) the total volume traded for the CAC 40 index constituting stocks over the day (ActivCAC); (viii) a measure of the staleness in the index values (Staleness); (ix) the index volatility (Volat); (x) the availability of the CAC 40 ETF (ETF) and (xi) the total volume traded for the CAC 40 ETF over the day (ActivETF). Log-likelihood test between the intercept-only and the AFT specifications is reported in Panel C. The null hypothesis for the $\chi^{2}$ test statistic is that the covariates do not improve the explanatory power of the model. Asterisks ${ }^{* * *},{ }^{* *},{ }^{*}$ denote the rejection of the null hypothesis at the $1 \%, 5 \%$ and $10 \%$ levels, respectively, in a bilateral test. The likelihood ratio statistics follows a $\chi^{2}$ distribution with 11 degrees of freedom.

\begin{tabular}{|c|c|c|c|}
\hline \multicolumn{4}{|c|}{ Panel A: Intercept-only specification } \\
\hline Variable & Coefficient & Std. error & Z-stat. \\
\hline$\mu$ (intercept) & $5.867^{* * *}$ & 0.0421 & 139.30 \\
\hline $\log \sigma$ & $0.858^{* * *}$ & 0.0131 & 65.30 \\
\hline \multicolumn{4}{|c|}{ Panel B: Accelerated Failure Time specification } \\
\hline Variable & Coefficient & Std. error & Z-stat \\
\hline$\mu$ (intercept) & $7.195^{* * *}$ & 0.3281 & 21.93 \\
\hline $\log \sigma$ & $0.793^{* * *}$ & 0.0135 & 58.93 \\
\hline ActivOpt & $-0.005^{* * *}$ & 0.0017 & -3.29 \\
\hline RatioOpt & $0.009^{* * *}$ & 0.0023 & 3.85 \\
\hline Mat2 & $0.590^{* * *}$ & 0.1275 & 4.62 \\
\hline Mat3 & $1.710^{* * *}$ & 0.1849 & 9.25 \\
\hline Moneyness & -0.005 & 0.0296 & -0.18 \\
\hline Direc & $0.404^{* * *}$ & 0.0785 & 5.15 \\
\hline ActivCAC & $-0.287^{* * *}$ & 0.0520 & -5.53 \\
\hline Staleness & 0.038 & 0.0358 & 1.06 \\
\hline Volat & $-0.023^{* * *}$ & 0.0036 & -6.51 \\
\hline ETF & $-0.635^{* * *}$ & 0.1219 & -5.21 \\
\hline ActivETF & $-5.667^{* *}$ & 2.8318 & -2.00 \\
\hline \multicolumn{4}{|c|}{ Panel C: Likelihood ratio test (Intercept-only vs AFT) } \\
\hline \multirow{3}{*}{$\begin{array}{l}\text { Intercept-only log-likelihood } \\
\text { AFT log-likelihood } \\
\chi^{2}(p \text {-value })\end{array}$} & & \multicolumn{2}{|c|}{$-7,665.4$} \\
\hline & & \multicolumn{2}{|c|}{$-7,455.3$} \\
\hline & & \multicolumn{2}{|c|}{$420.22(<0.001)$} \\
\hline
\end{tabular}




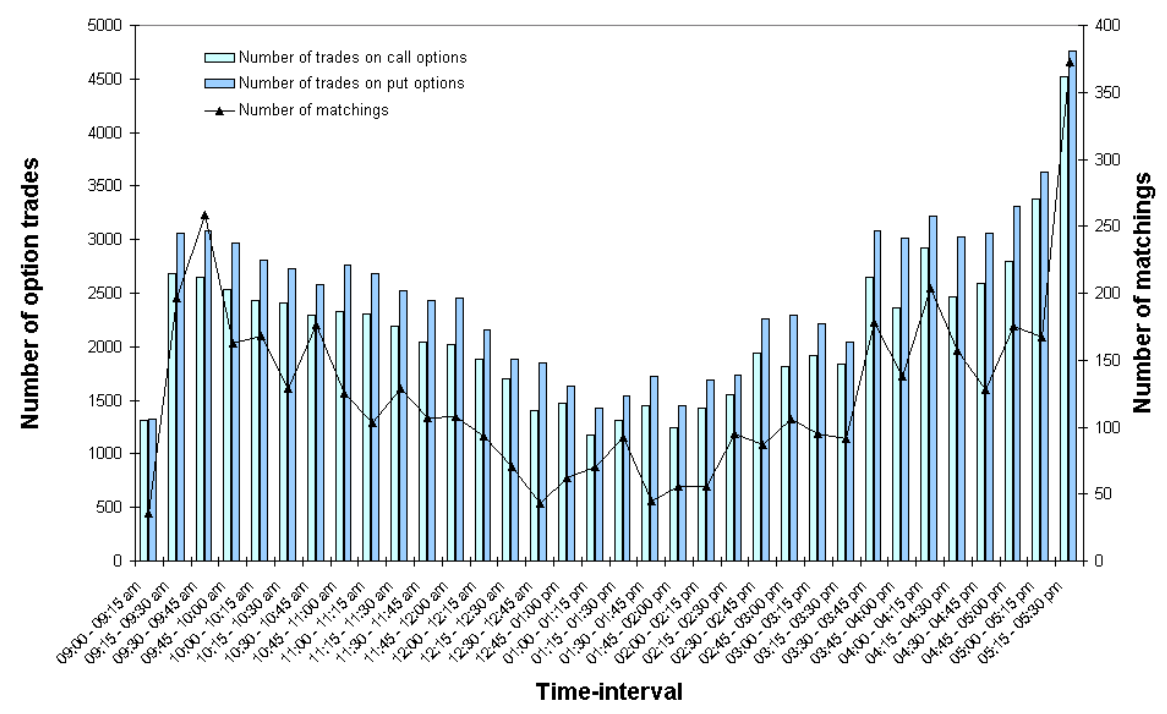

Figure 1: Intradaily distributions of call transactions, put transactions and put-call parity synchronous pairings
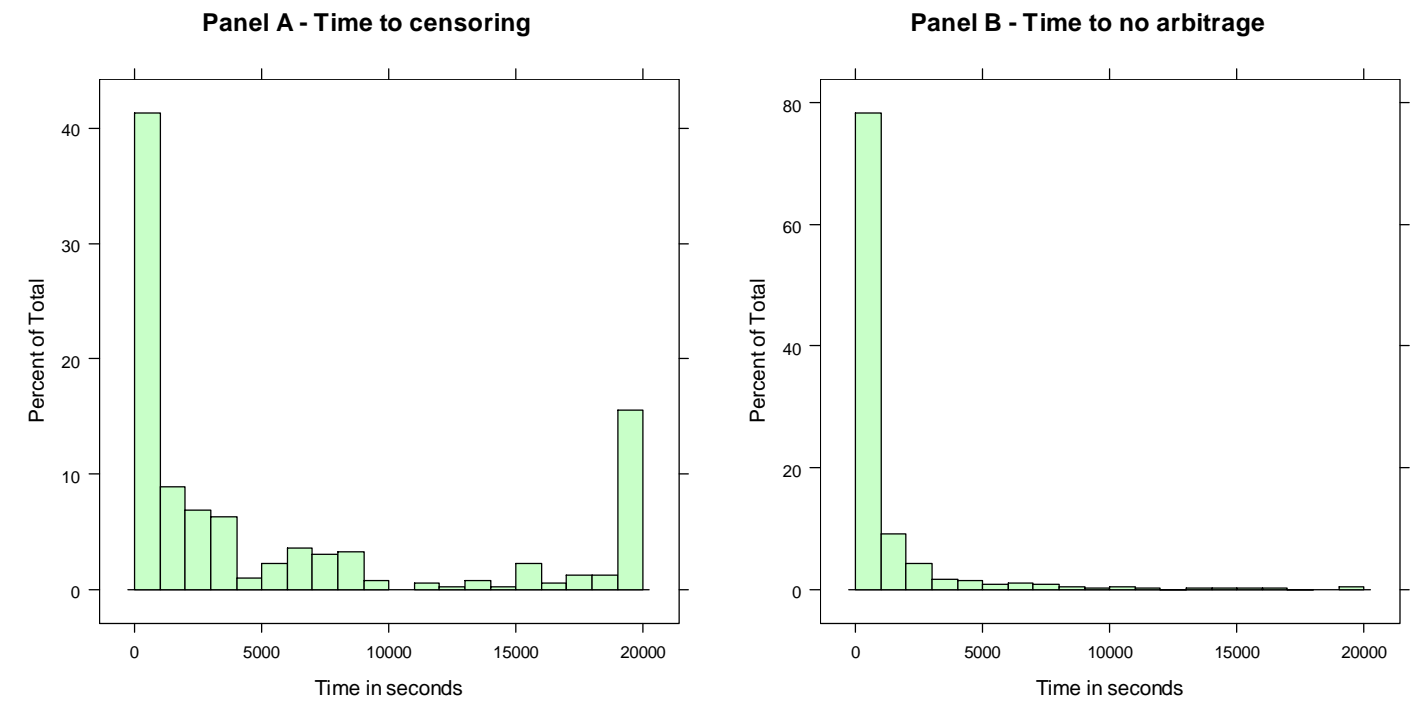

Figure 2: Empirical distributions of times to censoring (left figure, 437 observations) and times to efficiency (right figure, 3,815 observations) 

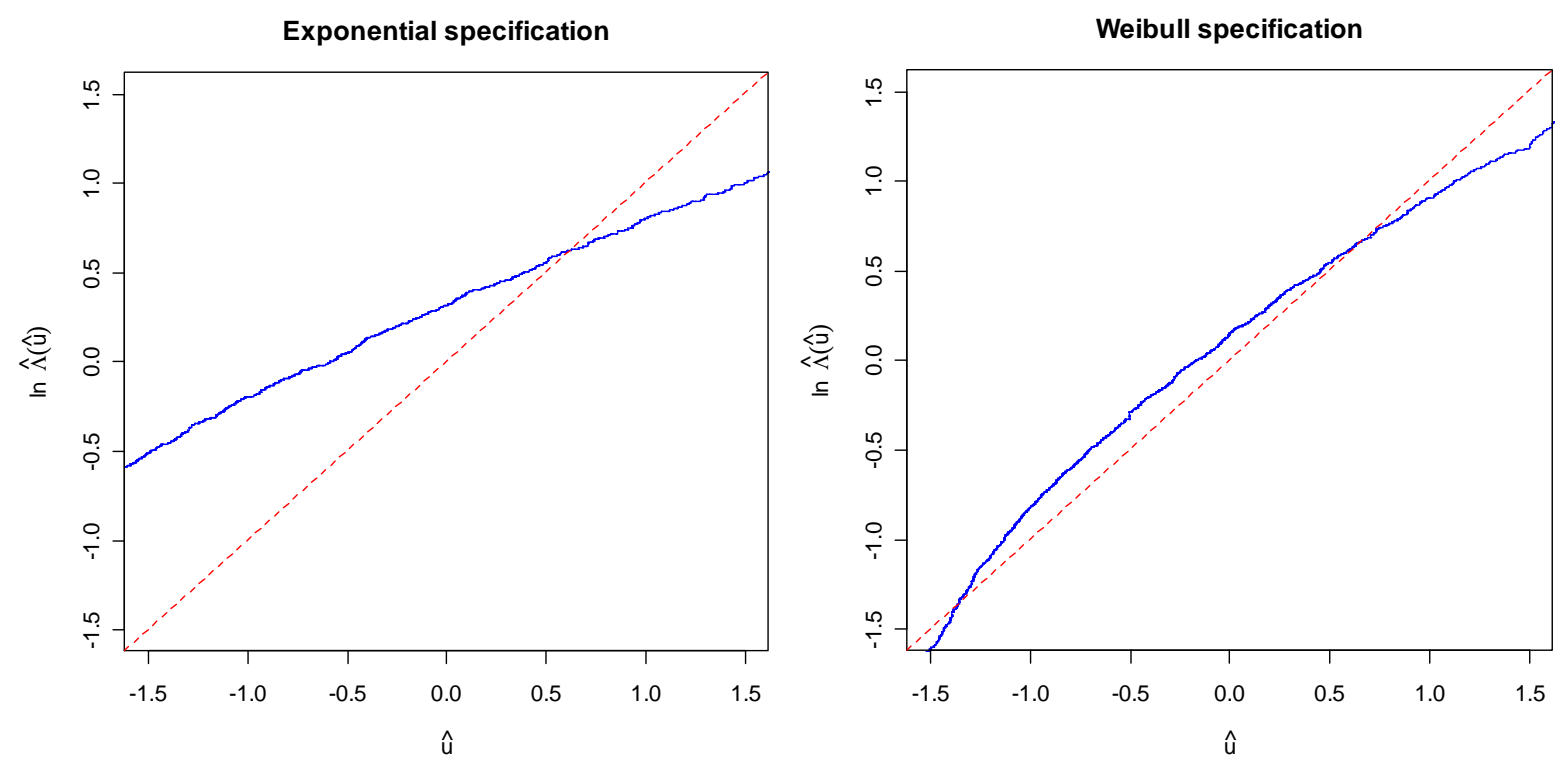

Figure 3: Goodness-of-fit graphical check

The $\log$ of the integrated hazard of the standardized residuals based on the Kaplan-Meier estimator of their empirical survival curve $(\ln [\hat{\Lambda}(\hat{u})])$ is plotted against the standardized residuals $(\hat{u})$. Under appropriate specification for the model, the graph should coincide with the plotted straight line. 

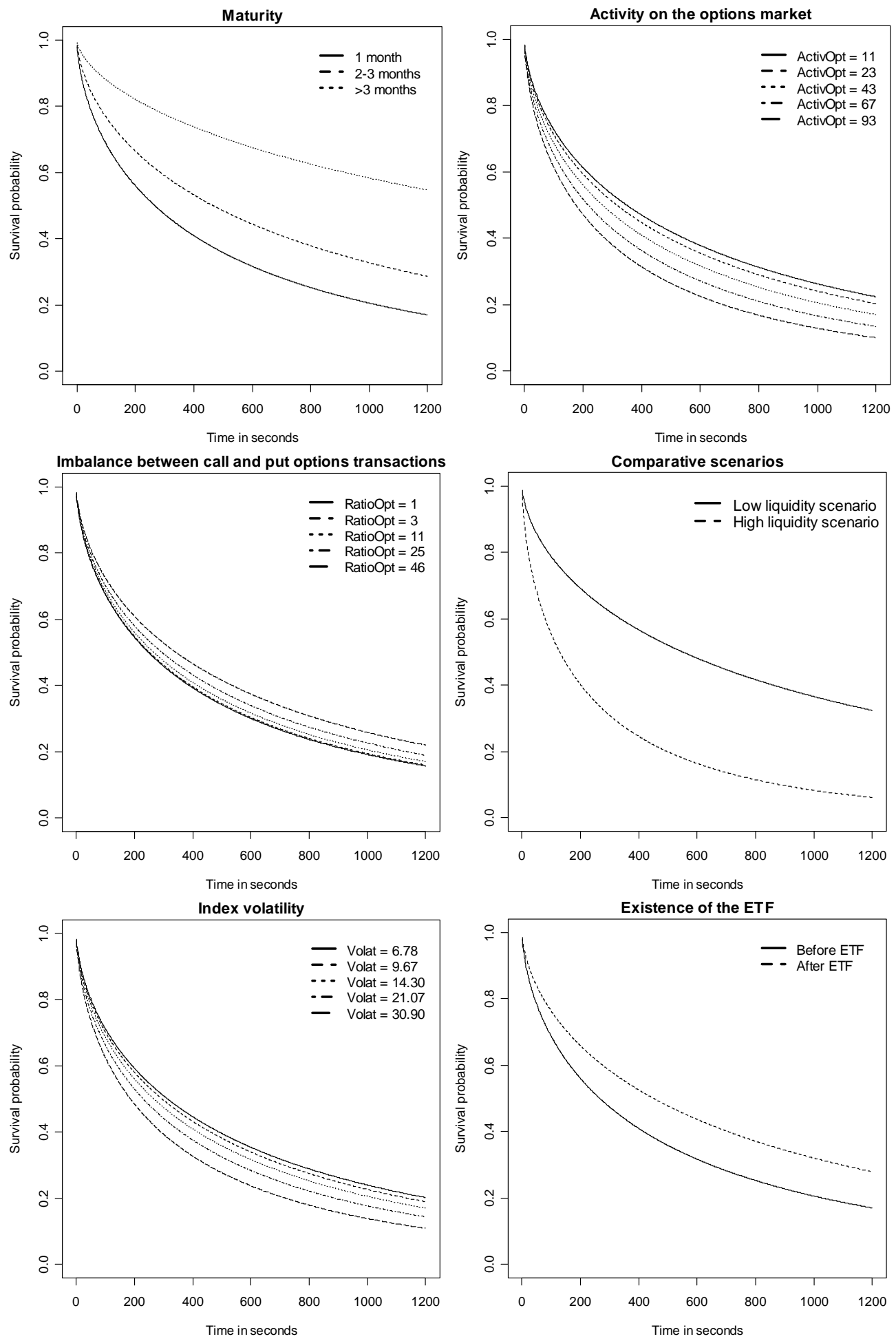

Figure 4: Sensitivity analysis

Estimated survival functions are plotted for different levels of the option series characteristics: maturity (Mat $i$ ), activity in the options market (ActivOpt), imbalances between call and puts (RatioOpt), a high liquidity/low liquidity scenario, volatility of the CAC 40 index (Volat) and explicit transaction costs (Costs). 